
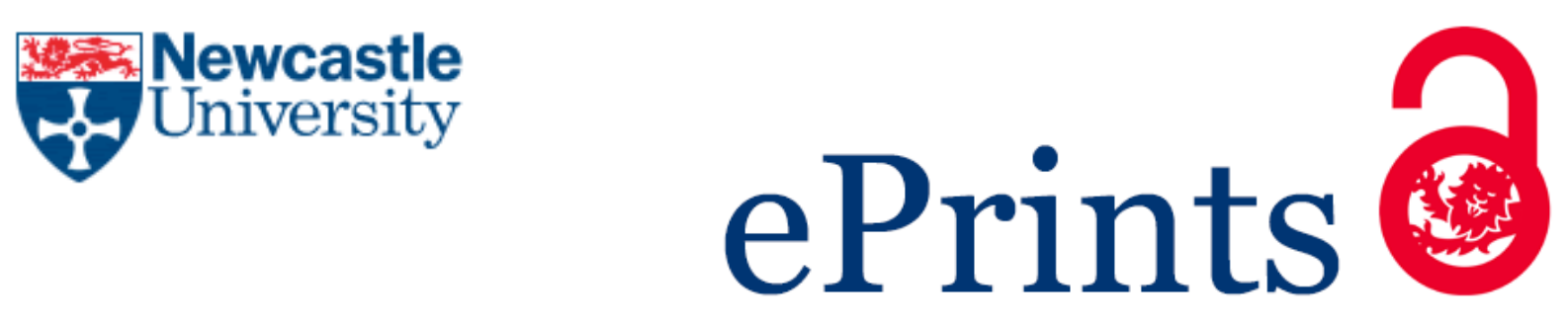

Mohamed MA, Lambert SM, Mecrow BC, Atkinson DJ, Smith AC.

An electrical machine with integrated drive LCL filter components.

In: 8th IET International Conference on Power Electronics, Machines and Drives (PEMD 2016). 2016, Glasgow, UK: The Institution of Engineering and Technology.

Copyright:

This is the authors' accepted manuscript of a paper that was presented at 8th IET International Conference on Power Electronics, Machines and Drives (PEMD 2016) conference, held 19-21 April 2016, Glasgow, UK

DOI link to article:

http://dx.doi.org/10.1049/cp.2016.0222

Date deposited:

$02 / 12 / 2016$ 


\title{
An Electrical Machine with Integrated Drive LCL Filter Components
}

\author{
M. A. Mohamed*, S. M. Lambert*, B. C. Mecrow*, D. J. Atkinson*, A. C. Smith† \\ *School of Electrical and Electronic \\ Engineering \\ Newcastle University, Newcastle Upon Tyne, \\ England, United Kingdom. \\ mohamed.mohamedencl.ac.uk \\ ${ }^{+}$School of Electrical and Electronic \\ Engineering \\ The University of Manchester, \\ Manchester, England, \\ United Kingdom
}

Keywords: Passive components; integrated motor drive; integrated ac input inductors.

\begin{abstract}
In recent years, integrated passive components technology has gained significant popularity in integrated drives research. An integrated drive may be considered to be a full mechanical integration of the machine, power electronic converter and passive components into a single package. This approach is important for applications such as traction motors, aerospace, electric vehicles and cars where space, mass or volume constraints are high. Incorporation of electromagnetic components, such as line filters, into electric machines can be achieved by sharing the existing machine's magnetic circuit with the filter component. In this paper part of an LCL line filter has been chosen to be integrated with a permanent magnet synchronous machine. An LCL filter has been selected as it has lower inductance compared to other input filter types such as LC and L filters. This paper also presents a several novel techniques for integrating the largest portion of LCL input power filter which is the 3-phase ac inductors located in the drive side producing a single mechanically packaged unit without significant increase in size and loss which in turn achieves high power density. Different integrated 3-phase input inductors designs have been simulated with finite element analysis to prove the effectiveness of integration of passives within the machine structure. In each case the design has been iteratively optimised to determine the optimal mass of copper and core for the integrated filter inductors targeting parity in power density when compared to a traditionally separated package. The paper demonstrates that an approach utilising a double slot machine with input filters wound into the outermost slots was the most appropriate choice in terms of power density compared to other proposed methods.
\end{abstract}

\section{Introduction}

The first generations of adjustable speed drives (ASDs) produced during the latter part of the $20^{\text {th }}$ century traditionally treated the various subsystems of the drive (electric machine, power electronics, passive converters etc.) as mechanically isolated entities. As ASD technology has matured the trend has been towards greater mechanical and operational integration of the various subsystems.

Integrated motor drives promise higher power density, the ability to directly replace direct on line (DOL) machines with ASDs, lower production and commissioning costs through single package installations and enhanced electromagnetic compatibility (EMC) due to the reduction in cable lengths carrying high frequency harmonics [1]. With specific reference to the topic of this paper there are previous examples in literature where considerable effort has been taken to integrate and reduce the size of passive components in integrated drives [10-13].

Grid connected drives are especially constrained by grid codes which dictate the levels of total harmonic distortion (THD), power factor and sag sensitivity which the drive produces. Most grid connected drives therefore include a line-side filter to supress the high frequency injection resultant from the power device switching.

In the most basic case the dc-link inductor is replaced with 3-phase ac inductors at the input of a front-end active rectifier which is typically used in 4-quadrant drives for active power converters. However, heavy iron chokes are still needed with the aim of improving interaction between the grid and the converter. The aim of these chokes is to mitigate the input current THD and to be more robust against unbalanced voltages. However, for high power applications, size of the chocks is large and the system dynamic response can be poorer [1-4]. More commonly, LCL filter are used instead of solely input filter inductors achieving a reduction of up to $50 \%$ of the required total inductance in the filter for comparable performance. A general schematic for a grid-connected electric drive system with an LCL input filter configuration is shown in Fig. 1.

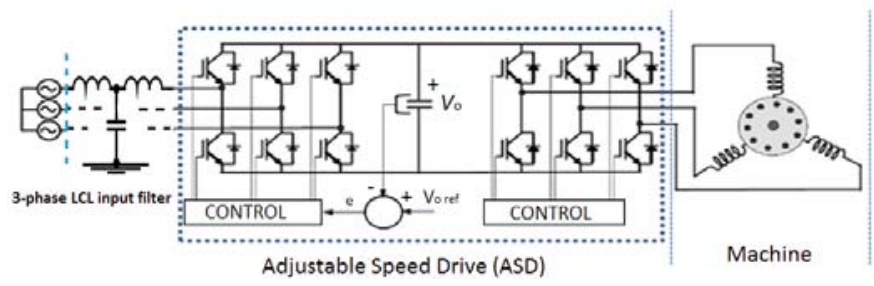

Fig. 1. Schematic of Electric Drive System

In [2], "LCL" filters offer optimum results in power ranges up to hundreds of kilovolt-amperes. This allows adequate attenuation of switching harmonics with the smallest value of inductors and capacitors compared to other types of input power filters, such as L-filter and LC-filter. The LCL filter consists of a grid side inductor, boost inductor (drive side), capacitor and damping resistor. The grid side inductor and capacitor are physically small in size compared to the drive side inductor, which accounts for the largest proportion of volume among the LCL filter components.

In the perspective of an integrated drive, the machine, power devices and passives are mechanically packaged together in a single unit. Since size of input ac line inductors is dictated by power rating of electric drives, the physical size of this inductor will scale with the magnitude of the drive power rating and as such 
become very large for higher power drives and may even dwarf the size of the machine in high speed drives.

For the purposes of this work two drive power ratings are considered with identical output torque (i.e. the underlying machine size is identical and the shaft speed is varied).

Five different techniques have been considered to examine the effectiveness of integration of the larger of the LCL filter inductors into the machine structure: auxiliary windings around the stator teeth, auxiliary windings around the stator core back, inner extra auxiliary slots (radially outwards of the primary slots), auxiliary slots around the outer surface of the stator (Double slot machine) and inductors placed at the corners of square laminations.

\section{Drive specifications}

Analysis on integrating the larger of the two input inductors of the LCL filter into the machine magnetics has been undertaken on two drive specifications where the underlying machine in each is identically dimensioned but operate at two different rated speeds. A $4.6 \mathrm{~kW}$ drive operating at 3,000RPM is identified as the baseline with a $38 \mathrm{~kW}$ input power, 25,000 RPM drive for comparison. The specifications for the two drives are given in Table 1 .

\begin{tabular}{|c|c|c|c|c|}
\hline $\begin{array}{c}\text { Drive } \\
\text { input } \\
\text { Power } \\
\text { (kW) }\end{array}$ & $\begin{array}{c}\text { Grid 1: Specifications of drives } \\
\text { Input } \\
\text { Current } \\
\text { (A RMS) }\end{array}$ & $\begin{array}{c}\text { Mach. } \\
\text { Pole } \\
\text { number }\end{array}$ & $\begin{array}{c}\text { Power } \\
\text { Density } \\
\text { (kW/litre) }\end{array}$ & $\begin{array}{c}\text { Machine } \\
\text { Speed } \\
\text { (RPM) }\end{array}$ \\
\hline 4.56 & 6.34 & 8 & 7.43 & 3000 \\
\hline 38 & 53 & 8 & 58.3 & 25000 \\
\hline
\end{tabular}

The assumption is made that the energy stored in the filter inductor (as per (1)) to be integrated scales linearly with the power rating of the drive. Therefore, the drive with higher power rating results in a larger size of input filter inductor. The storage energy is scaled by factor of 8.3 based on the variance in input power.

$$
\text { Energy stored }=\frac{1}{2} L_{2} \hat{I}_{L 2}^{2}
$$

Where $L_{2}$ is the drive-side inductor and $\hat{I}_{L 2_{1}}$ is the peak fundamental current in $L_{2}$.

As the underlying machine size remains the same between the two drive specifications the integration of the inductors for the higher power drives is more challenging since the inductor will be larger in relation to the underlying machine.

\section{LCL filter design and modelling}

An LCL filter a common interference between a voltage source rectifier (VSR) and the utility grid. This type of filter is attractive and widely used due it offering smaller size in comparison to other filter options. The LCL filters can render better attenuation of switching harmonics and smaller total input inductance compared to that of $\mathrm{L}$ type filters.

The per-phase equivalent model of an LCL filter is outlined in [6 \& 7] and is shown in Fig. 2. $\mathrm{L}_{1}$ and $\mathrm{L}_{2}$ are the grid side and drive side inductors respectively, $\mathrm{C}_{\mathrm{f}}$ is the filter capacitance and series a damping resistance is denoted as $\mathrm{R}_{\mathrm{d}}$. In [7], the transfer function of the LCL filter is given in the form

$$
\mathrm{T}_{\mathrm{LCL}}=\frac{I_{L 1}}{\mathrm{~V}_{\mathrm{SW}}}
$$

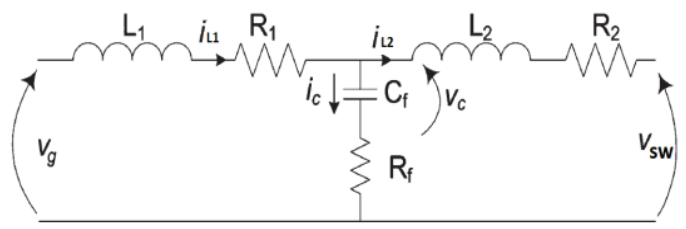

Fig. 2. LCL filter per-phase model

For this analysis a stiff, ideal voltage source is assumed with a perfectly sinusoidal voltage profile. The transfer function of the LCL filter may be derived by using the methodology presented in [6] with and without a damping resistor assuming the ideal voltage source (the grid) is a short (i.e. $V_{g}=0$ ) and considering the fundamental switching voltage $V_{s w}$.

$$
\begin{gathered}
T_{L C L}(s)=\frac{1}{L_{1} C_{f} L_{2} S^{3}+\left(L_{1}+L_{2}\right) S} \\
T_{d L C L}(s)=\frac{C_{f} R_{f} S+1}{L_{1} C_{f} L_{2} S^{3}+C_{f}\left(L_{1}+L_{2}\right) R_{f} S^{2}+\left(L_{1}+L_{2}\right) S}
\end{gathered}
$$

The LCL filter design should be designed to meet grid standards such as IEEE-519 and IEEE-1547 which impose harmonic injection constraints [7-10] and to avoid a poor dynamic response of the system.

The specification of the three-phase power factor correction (PFC) rectifiers are shown in Table 2 .

Table 2: Specification of three phase active rectifiers

\begin{tabular}{|c|c|c|c|c|}
\hline Parameter & Variable & $\begin{array}{c}\text { Value } \\
\mathbf{( 4 . 5 6 k W} \\
\text { drive) }\end{array}$ & $\begin{array}{c}\text { Value } \\
\mathbf{( 3 8 k W} \\
\text { drive) }\end{array}$ & Unit \\
\hline $\begin{array}{c}\text { Drive input } \\
\text { power }\end{array}$ & $\boldsymbol{P}$ & 4.56 & 38 & $\mathrm{~kW}$ \\
\hline $\begin{array}{c}\text { Input phase } \\
\text { voltage }\end{array}$ & $V_{p h}$ & 240 & 240 & $\mathrm{~V}$ \\
\hline $\begin{array}{c}\text { Grid } \\
\text { Frequency }\end{array}$ & $f_{g}$ & 50 & 50 & $\mathrm{~Hz}$ \\
\hline $\begin{array}{c}\text { DC-link } \\
\text { voltage }\end{array}$ & $V_{D C}$ & 750 & 750 & $\mathrm{~V}$ \\
\hline $\begin{array}{c}\text { Input grid } \\
\text { current }\end{array}$ & $I_{g}$ & 6.34 & 53 & $\begin{array}{c}\mathrm{A} \\
(\mathrm{RMS})\end{array}$ \\
\hline $\begin{array}{c}\text { Switching } \\
\text { Frequency }\end{array}$ & $f_{S w}$ & 40 & 40 & $\mathrm{kHz}$ \\
\hline
\end{tabular}

Current waveforms for each of the LCL filter components are shown in Fig 3. A minimum current ripple design constraint of $10 \%$ of the peak fundamental current on the drive side is imposed on the filter design to limit harmonic injection to the supply [6].

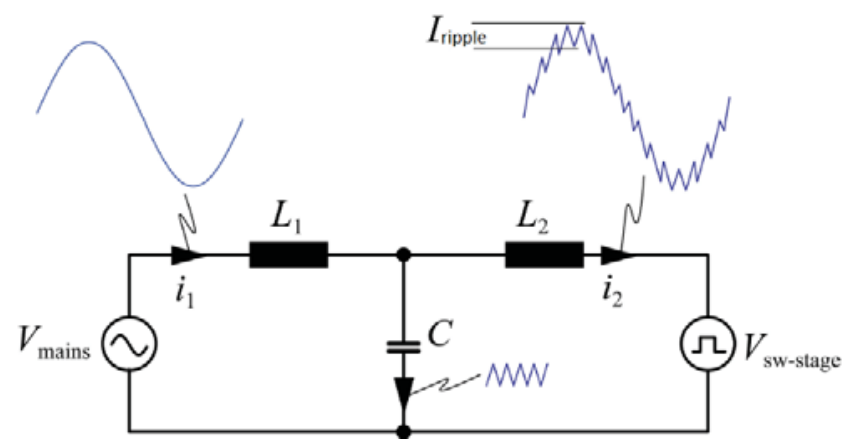

Fig. 3. Current waveforms for each filter component

The calculation of ripple current is given in (5) and uses the peak input current as calculated from (6) [6]; 


$$
\begin{aligned}
I_{\text {ripple }} & \leq 0.1 \hat{I}_{L 1_{1}} \\
\hat{I}_{\mathrm{L} 1_{1}} & =\frac{P \sqrt{2}}{3 V_{p h}}
\end{aligned}
$$

The minimum value of $L_{2}$ is calculated as follows;

$$
L_{2 \min }=\frac{V_{d c}}{16 f_{\text {sw }} I_{\text {ripple }}}
$$

The fundamental reactive power which is absorbed by the filter capacitor should be less than $5 \%$ of the rated active power of the voltage source rectifier to avoid the system from excess power factor decrease, [2] and [11].

$$
C_{f}<5 \% C_{b}
$$

where $C_{b}$ is base capacitance and can be derived from defining a base impedance $Z_{b}$ as following [2] and [6].

$$
\begin{gathered}
Z_{b}=\frac{E_{n}{ }^{2}}{P} \\
C_{b}=\frac{1}{\omega_{g} Z_{b}}
\end{gathered}
$$

Where $E_{n}$ is the line-line RMS voltage and $\omega_{g}$ is the grid angular frequency. The grid side inductance can be calculated based on the capacitor value $C_{f}$ and the switching frequency considering an attenuation factor $K_{a}$, which should be approximately $20 \%$, [2], [6] and [7].

$$
L_{1}=\frac{\sqrt{\frac{1}{K_{a}{ }^{2}}+1}}{C_{f} 2 \pi f_{s w}{ }^{2}}
$$

In addition, at the resonant frequency, $\omega_{\text {res }}\left(2 \pi f_{\text {res }}\right)$, the filter impedance is zero, thus inserting a series resistor with the shunt capacitor is necessary to prevent resonance oscillation. The damping resistance $R_{d}$ and $\omega_{\text {res }}$ can be calculated as described in [2] and [6].

$$
\begin{aligned}
\omega_{\text {res }} & =\sqrt{\frac{L_{1}+L_{2}}{L_{1} L_{2} C_{f}}} \\
R_{d} & =\frac{1}{3 \omega_{\text {res }} C_{f}}
\end{aligned}
$$

The LCL filter component values for the drives considered in this paper are given in Table 3 .

Table 3: Input LCL filter Parameters

\begin{tabular}{|c|c|c|c|c|}
\hline Parameter & Variable & $\begin{array}{c}\text { Value } \\
\mathbf{( 4 . 5 6 k W} \\
\text { drive) }\end{array}$ & $\begin{array}{c}\text { Value } \\
\mathbf{( 3 8 k W} \\
\text { drive) }\end{array}$ & Unit \\
\hline $\begin{array}{c}\text { Grid Side } \\
\text { Inductance (per } \\
\text { phase) }\end{array}$ & $\boldsymbol{L}_{\mathbf{1}}$ & 37.56 & 5 & $\mu \mathrm{H}$ \\
\hline $\begin{array}{c}\text { Drive Side } \\
\text { inductance } \\
\text { (per phase) }\end{array}$ & $\boldsymbol{L}_{\mathbf{2}}$ & 1.31 & 0.16 & $\mathrm{mH}$ \\
\hline $\begin{array}{c}\text { Capacitor } \\
\text { (per phase, star } \\
\text { connected) }\end{array}$ & $\boldsymbol{C}_{\boldsymbol{f}}$ & 2.53 & 21 & $\mu \mathrm{F}$ \\
\hline $\begin{array}{c}\text { Damping } \\
\text { Resistance } \\
\text { (per phase) }\end{array}$ & $\boldsymbol{R}_{\boldsymbol{d}}$ & 1.27 & 0.4 & $\Omega$ \\
\hline
\end{tabular}

\section{Base machine \\ and \\ separate \\ inductor specifications}

For the purposes of this study the dimensions of the underlying machine in both the $4.56 \mathrm{~kW}$ and $38 \mathrm{~kW}$ are identical and are outlined in Table 4.

Table 4: Machine specifications

\begin{tabular}{|c|c|c|c|c|}
\hline Parameter & Variable & $\begin{array}{c}\text { Value } \\
\mathbf{( 4 . 5 6 k W} \\
\text { drive) }\end{array}$ & $\begin{array}{c}\text { Value } \\
\mathbf{( 3 8 k W} \\
\text { drive) }\end{array}$ & Unit \\
\hline Shaft speed & $S$ & 3000 & 25000 & RPM \\
\hline Pole Number & $n_{p}$ & 8 & 8 & \\
\hline Tooth number & $n_{t}$ & 12 & 12 & $\mathrm{~mm}$ \\
\hline Rotor diameter & $d_{r}$ & 62 & 62 & $\mathrm{~mm}$ \\
\hline $\begin{array}{c}\text { Machine } \\
\text { lamination } \\
\text { diameter }\end{array}$ & $O D_{m}$ & 103 & 103 & \\
\hline Winding type & & Concentrated & Concentrated & \\
\hline
\end{tabular}

As a basis for comparison the volume for stand-alone inductors combined with motor volume of the values derived in section 3 for the $4.56 \mathrm{~kW}$ and $38 \mathrm{~kW}$ drive have been calculated as $6.549 \mathrm{E}-4 \mathrm{~m}^{3}$ and $9.46 \mathrm{E}-4 \mathrm{~m}^{3}$ respectively.

\section{Integrated 3-phase ac inductors within a machine stator}

The geometry of the integrated inductor is dictated by the machine design and the value of inductance is governed by the power rating of the drive. In the previous sections the required value of inductance for the drive-side inductor of the LCL filter was calculated as $1.31 \mathrm{mH}$ and $0.16 \mathrm{mH}$ for the $4.56 \mathrm{~kW}$ and $38 \mathrm{~kW}$ dries respectively.

In this paper five techniques for integrating the drive-side inductor into the machine topology have been investigated for both power levels with the resulting increase in outer diameter (OD), total volume and copper loss shown in Table 5.

\subsection{Options (a) and (b) - Auxiliary windings around stator teeth and core back}

These approaches are driven by a desire to maintain the basic structure of the machine magnetics by utilising the same slots as the machine windings. In option (a) additional windings are wound around the teeth of the machine in the same way as the main torque producing windings. In option (b) windings are made around the core-back of the machine. In both cases the magnetic flux path includes the machine airgap and rotor and hence the additional size resulting from the additional turns in the slot is heavily dictated by the airgap. In order to cancel any coupling between the auxiliary windings (filter windings) and the rotor, as well as the main, torque producing windings a different pole number is selected for the auxiliary windings to that of the main machine. Different combinations of pole number for machine and auxiliary windings result in either balanced or unbalanced magnetic poles. In order to achieve a balanced case, the machine and auxiliary pole numbers must be separated by a multiple of two pole pairs and hence the pole number for the auxiliary windings $n_{a}$ and the machine windings $n_{m}$ are governed by (12).

$$
n_{a}-n_{m}=4 x
$$


Table 5: Different topologies for integrating an electric drive

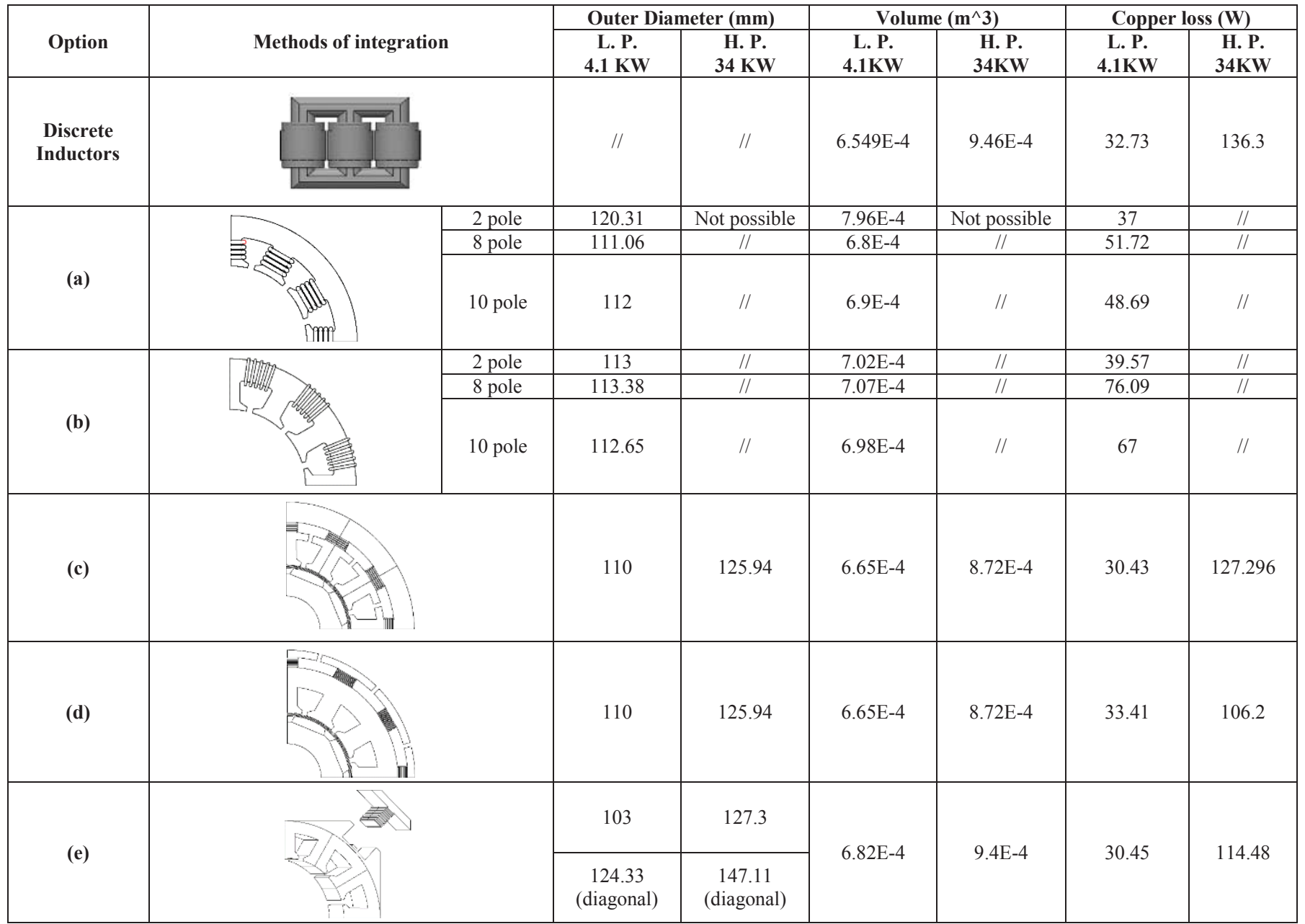

where $x$ is an integer constant. The equations governing the number of turns in the additional windings are given in 15-17, [15].

$$
\begin{gathered}
N I=\emptyset \mathcal{R}_{\text {eq }} \\
\mathcal{R}_{\text {eq }}=\mathcal{R}_{\text {gap }}+\mathcal{R}_{\text {steel }}=\frac{1}{\mu_{\circ} A_{\text {min }}}\left(L_{g}+\frac{L_{m}}{\mu_{r}}\right)
\end{gathered}
$$

The inductance of the auxiliary windings is defined as

$$
L=\frac{\psi}{I}=\frac{N^{2}}{\mathcal{R}_{e q}}
$$

where NI is the magneto-motive force (amp-turn), $\varnothing$ the magnetic flux resultant from the auxiliary winding, $\mathcal{R}_{e q}$ the equivalent reluctance of the auxiliary magnetic circuit, $L_{m}$ the magnetic flux path length, $L_{g}$ the air gap length, $A_{\min }$ is the minimum crosssection area of steel in the magnetic path and $\psi$ is the flux linkage of the auxiliary winding.

The tooth width and stator core back of the original underlying machine are therefore rescaled based on the equations (18 and 19) [14] and [15].

$$
\begin{aligned}
& \frac{1}{2} \emptyset=B_{T} A_{c b} \\
& W_{T} B_{T}=B_{g} \tau_{s}
\end{aligned}
$$

where $B_{T}$ the tooth flux density, $A_{c b}$ the core back area, $W_{T}$ the tooth width, $B_{g}$ the air gap flux density and $\tau_{s}$ the stator slot pitch.

As number of poles of the auxiliary windings changes, the magnetic path length will be changed and so the number of turns of the auxiliary windings will be varied based on the equations (10-12). Integration methods (a) and (b) have been simulated for different number of poles. To avoid steel saturation the machine stator teeth and core back thickness will be increased in order to avoid saturation and the increased dimensions are shown in Table 5.

The results shown in Table 5 indicate that options (a) and (b) do not appear promising as the total integrated volume is considerably larger than for the case for discrete machine and filter inductor. In addition, the restriction of choosing number of poles for the auxiliary windings reduces flexibility and despite mismatching the pole numbers the geometry of the machine means that cross-coupling between the auxiliary and main windings and rotor can never be totally removed.

\subsection{Options (c) and (d) - Additional slots}

In the first two methods, the air gap between rotor and stator formed part of the magnetic circuit for the integrated inductors. As it is relatively large and restricted by the machine design this severely limits the design choices available for optimisation of these integration options and results in a far higher number of turns 
than is the case for the separate inductor - hence the significant volume increase versus the separate inductor case.

The primary goal from options (c) and (d), as shown in Table 5, is to remove the machine airgap from the main auxiliary magnetic circuit path and utilise a separate slot with geometries not dictated by the machine magnetics. This method gives greater control over the auxiliary magnetic circuit reluctance as the auxiliary gaps can be modified without effecting the performance of the machine and therefore the amount of auxiliary copper and hence ultimately the increase in volume is more governable.

Option (c) has achieved a reasonable volume but the integrated inductors still share the same path of magnetic flux of the machine windings. Therefore, there is still the possibility for cross-coupling between them as demonstrated in Fig. 5.

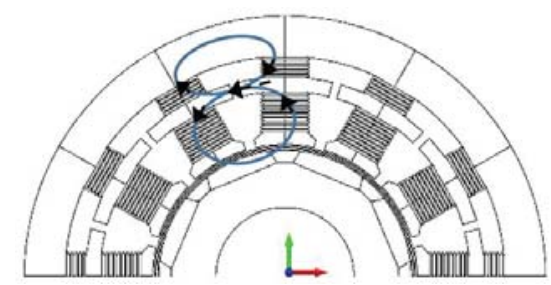

Fig. 5. Magnetic flux cross-coupling behaviour between the auxiliary and machine windings for option (c)

In order to avoid unwanted harmonic injection resulting from the cross-coupling between machine and auxiliary windings, the extra slots have been redistributed to the outer surface of the stator. In this arrangement the two magnetic paths have significantly less coupling as demonstrated in Fig 6.

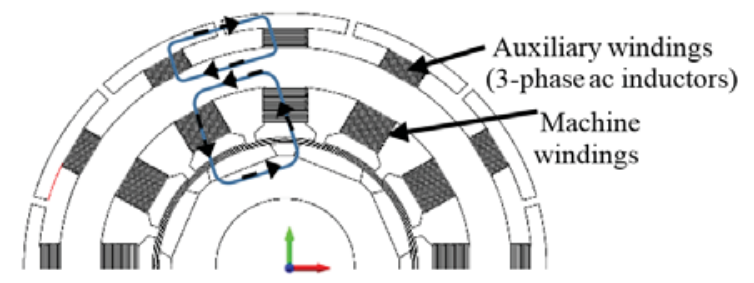

Fig. 6. Geometry of a half model of double slot machine (Incorporation of 3-phase ac inductors into the machine)

The dimensions of these two options are more-or-less identical and smaller than for options (a) and (b) however, due to the reduced likelihood of winding coupling the outer slot design is preferred. A $3 \mathrm{D}$ representation of the outer slot design is shown in Fig 7.

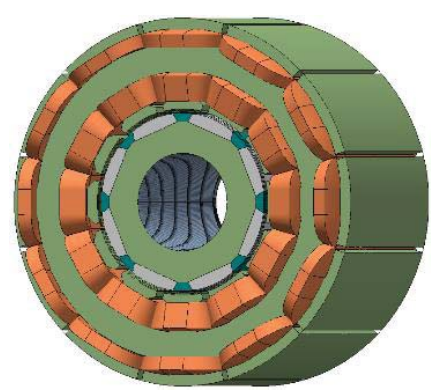

Fig. 7. 3D representation of auxiliary slot mounted inductors

\subsection{Option (e) - Corner windings}

In this approach the circular form of the stator laminations is converted to a square. The three-phase auxiliary windings are formed of three coils each situated in a corner of this square.
Fig 8 demonstrates the principle of integrating the auxiliary windings into the corners of the squared profile.

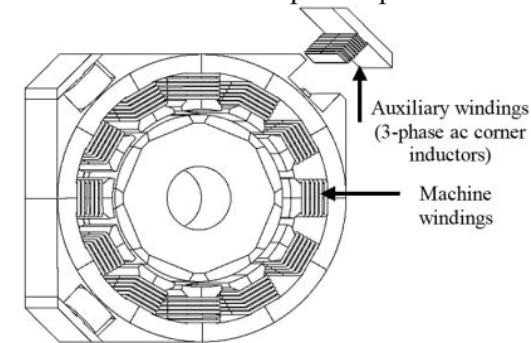

Fig. 8. Utilization of motor's corners for integrating ac inductors

\subsection{Design options summary}

The investigations into the increased volume, OD and copper loss resulting from integration of the larger of the two filter inductors of an LCL filter for the two drives has shown that the additional slots achieve the best performance ahead of the corner and main slot mounted windings. The outer additional slot design is therefore the design model which has been selected for the continuation of this work. As expected the higher speed drive presents a greater design challenge for integration of the filter inductor since as its size relative to the basic motor is so much larger. For this reason the analysis continues for integration of the $38 \mathrm{~kW}$ drive solely.

\section{Finite Element Analysis Results}

The integrated motor with additional outer slots to form grid side filter inductors has been simulated using Infolytica MagNet software. A contour plot of a 2D simulation of the integrated system is shown in Fig 9. In this case both the machine's torque producing windings and the auxiliary windings are energised.

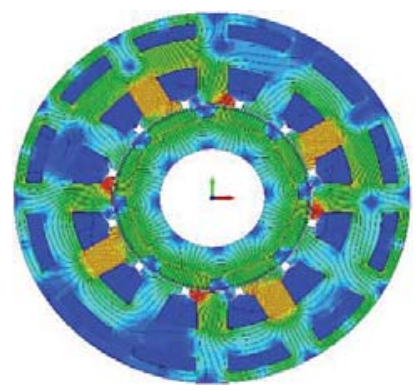

Fig. 9. Contour plot of integrated motor drive

The three-phase integrated filter inductors are simulated with a driven current of 53 A RMS. The resulting inductor voltage is shown in Fig 10 as $2.67 \mathrm{~V}$ RMS. The phase inductance can then be calculated from equation $(20)$ as $0.16 \mathrm{mH}$ which is as specified in Table 3 [2], [6] and [15].

$$
V_{L}=\omega L i
$$

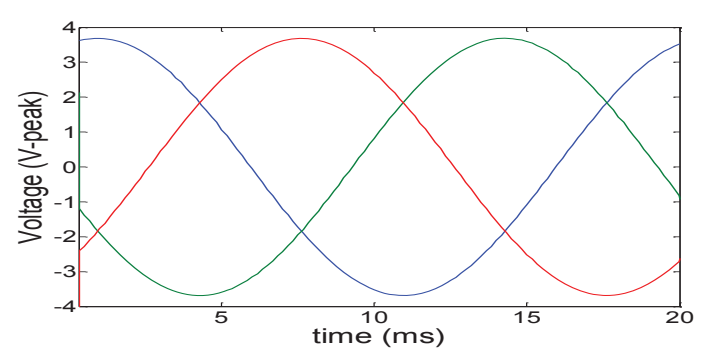

Fig. 10. Three phase voltage of the integrated ac input inductors 


\section{Experimental results}

A three tooth motorette has been constructed to assess the performance of the outer slot concept for an integrated filter inductor. The constructed motorette is shown in Fig 11. \& 12.

Single tooth inductance was calculated by passing a $50 \mathrm{~Hz}$ current through the auxiliary and observing the coil voltage. In the design each phase is formed of four parallel connected coils thus the total inductance for a single tooth should be $0.64 \mathrm{mH}$. The measured results show that the inductance of the single tooth motorette at rated current is 0.65 , full current range results are shown in Fig. 13.

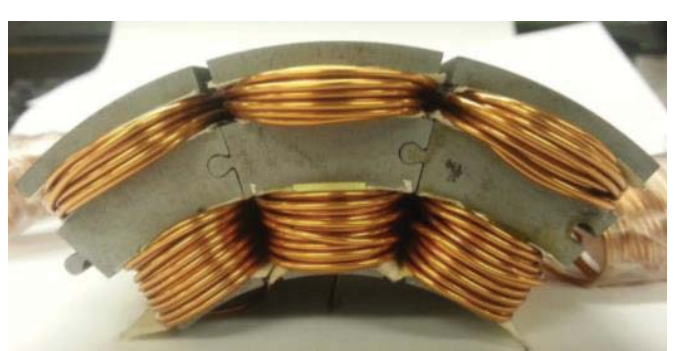

Fig. 11. Three tooth motorette to test single tooth auxiliary coil

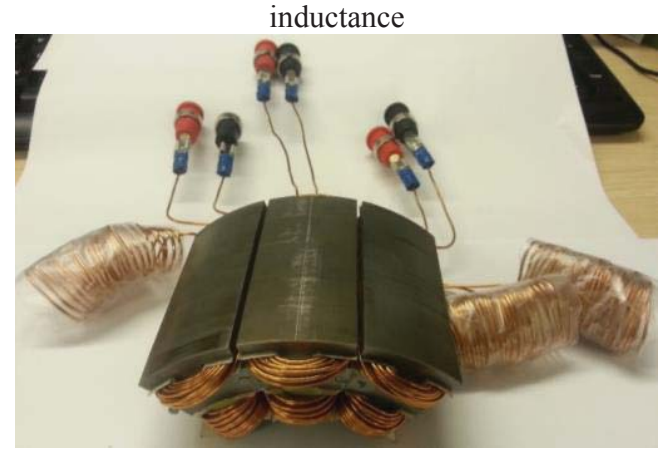

Fig. 12. Three tooth motorette with test leads

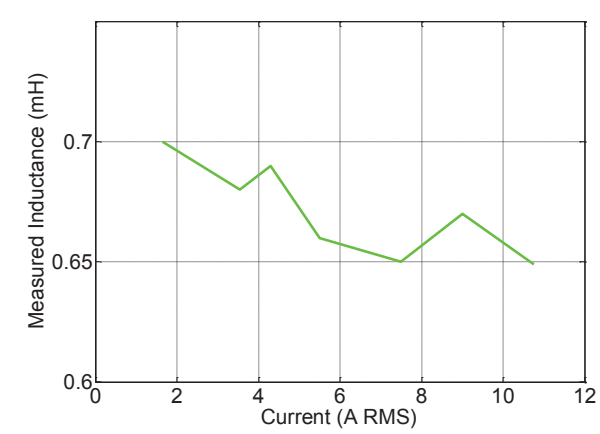

Fig. 13. Single tooth inductance measurements of motorettes

\section{Conclusion and Future work}

This paper has shown that there are different methods to incorporate the larger 3-phase drive-side inductors of an LCL input power filter into electric machines. A design procedure for 3-phase LCL filters has been introduced demonstrating a lower total inductance compared to other input line filters such as L and LC filter types. Two electric drive specifications with identical underlying machines have been considered for five integration techniques. The integrated component volumes, OD and copper loss has been compared to the traditional discrete component case and shown to be comparable for the case of additional slots to house the auxiliary windings. The auxiliary winding design has been analytically generated, validated through FEA and finally experimentally confirmed through testing of a motorette.

Although a topic not considered in this paper the thermal design of the integrated motor and filter inductor has been undertaken in parallel and it is the authors' intention to publish this process at a later date. Other further work will include realisation of a full integrated drive including the other filter components, the full electric machine, power electronic converter and control hardware.

\section{Acknowledgements}

This work was in part supported by the Engineering and Physical Sciences Research Council (EPSRC) Centre for Power Electronics (Grant references: EP/K035304/1, EP/K034987/1)

\section{References}

[1] C. Klumper, F. Blaabjerg, P. Thoegersen. "Alternate ASDs: evaluation of the converter topologies suited for integrated motor drives", Industry Applications Magazine, IEEE, Volume: 12, PP. 71 - 83, (2006).

[2] M. Liserre, F. Blaabjerg, S. Hansen. "Design and Control of an LCLFilter Based Three-Phase Active Rectifier", Industry Applications, IEEE Transactions on Volume: 41, PP. 1281 - 1291, (2005).

[3] K. Lee, T. M. Jahns, D. W. Novotny, T. A. Lipo, W. E. Berkopec, V. Blasco. "Impact of Inductor Placement on the Performance of Adjustable Speed Drives Under Input Voltage Unbalance and Sag Conditions", Electric Machines and Drives, IEEE International Conference PP. $1408-1414,(2005)$.

[4] K. Lee, T. M. Jahns, W. E. Berkopec, T. A. Lipo. "Closed-Form Analysis of Adjustable-Speed Drive Performance Under Input-Voltage Unbalance and Sag Conditions", Journal, Volume: 42, PP. 733 - 741, (2006).

[5] L. Yongqiang, X. Dianguo, S. R. Hadianamrei, M. Hongfei. “A Novel Design Method of LCL Type Utility Interface for Three-Phase Voltage Source Rectifier", Power Electronics Specialists Conference, PP. 313 317, (2005).

[6] A. Reznik, M. G. Simoes, A. Al-Durra, S. M. Muyeen. "LCL Filter Design and Performance Analysis for Grid-Interconnected Systems", volume: 50, PP. 1225 - 1232, (2014).

[7] 519-1992 IEEE Recommended Practices and Requirements for Harmonic Control in Electrical Power Systems, IEEE Std 519-1992, (1993).

[8] 519-2014 IEEE Recommended Practices and Requirements for Harmonic Control in Electrical Power Systems, IEEE Std 519-2014, (2014).

[9] IEEE Standard Conformance Test Procedures for Equipment Interconnecting Distributed Resources with Electric Power Systems, IEEE Std 1547.1-2005, (2005).

[10] Z. Ning, K. Jinsong, X. Dewei, W. Bin, X. Yuan. "A novel integrated $\mathrm{AC}$ choke for common-mode voltage suppression in power converter system", PP. 1030 - 1035, (2011).

[11] B. M. Nee, P. L. Chapman. "Integrated Filter Elements in Electric Drives", PP. 148 - 153, (2007).

[12] S. D. Garvey, W. T. Norris, M. T. Wright. "The role of integrated passive components in protectingmotor windings", Electric Power Applications, Volume: 147, PP. $367-370,(2000)$.

[13] R. M. Tallam, G. L. Skibinski, T. A. Shudarek, R. A. Lukaszewski, "Integrated Differential-Mode and Common-Mode Filter to Mitigate the Effects of Long Motor Leads on AC Drives", Industry Applications, volume: 47, PP. 2075 - 2083, (2011).

[14] J. Pyrhonen, T. Jokinen, V. Hrabovcova, "Design of Rotating Electrical Machines", 2014 John Wiley \& Sons, Ltd, ISBN: 978-1-118-58157-5.

[15] D. Hanselman, "Brushless Motors Magnetic Design, Performance, and Control”, E-Man Press LLC, 2012. 